\title{
Parasite Contamination of Freshly Harvested Vegetables from Selected Markets Located within Kano Metropolis
}

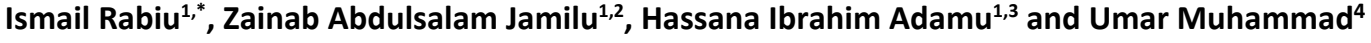 \\ ${ }^{1}$ Department of Microbiology, College of Natural and Pharmaceutical Sciences, Bayero University, Kano State, Nigeria \\ ${ }^{2}$ Department of Science Laboratory Technology, Jigawa State Polytechnic, Dutse, Jigawa State, Nigeria \\ ${ }^{3}$ Department of Microbiology, Faculty of Natural Sciences, Kogi State University, Anyigba, Kogi State, Nigeria \\ ${ }^{4}$ Department of Biotechnology, faculty of science, Nigerian Defence Academy, kaduna state, Nigeria
}

*Corresponding author: Ismail Rabiu, Department of Microbiology, College of Natural and Pharmaceutical Sciences, Bayero University, P.M.B. 3011, Kano State, Nigeria, Tel: +2347037515320; E-mail: rtismail24@gmail.com

Received: 18 May, 2021 | Accepted: 16 Jun, 2021 | Published: 24 Jun, 2021

Citation: Rabiu I, Jamilu ZA, Adamu HI, Muhammad U (2021) Parasite Contamination of Freshly Harvested Vegetables from Selected Markets Located within Kano Metropolis. J Biochem Analyt Stud 5(1): dx.doi.org/10.16966/2576-5833.126

Copyright: (C) 2021 Rabiu I, et al. This is an open-access article distributed under the terms of the Creative Commons Attribution License, which permits unrestricted use, distribution, and reproduction in any medium, provided the original author and source are credited.

\begin{abstract}
Nigeria is among the countries with the highest population cases of infections with intestinal parasites in sub-Saharan Africa. The increase in consumption of leafy and root vegetables by population in Kano metropolis necessitated the need for a study to assess the types and scope of these parasitic organisms in vegetables consume in urban Kano. Vegetables produce obtained from most markets within Kano metropolis are mostly sourced from nearby irrigation farms that used relatively contaminated waters which provides suitable growth condition for disease causing organisms. This research study determines the presence of parasites of health importance and their level of contamination in selected vegetables (cabbage, lettuce Cucumber, carrot and onions) sold at various markets in Kano metropolis. Vegetable samples were purchased randomly under normal purchased conditions and about $200 \mathrm{~g}$ each was weighed and washed according to the generally used method for washing vegetables. The samples were eluted followed by sonication in an already prepared buffered solution, filtered and examined for the presence of cysts, oocysts, and helminthes eggs and larvae. The eggs/cysts of Ascaris lumbricoides, Entamoeba species, Giardia intestinalis and Trichuiris species were observed. Among all the four markets involved in the study, "GanaKwari market recorded the highest number of eggs/cysts, been present in all the samples, followed by Kwa-kwaci Market with the presence of eggs/cysts in all the samples excluding cabbage. These are followed by Kofar Naisa market with all the samples contaminated but with less number of eggs/cysts. However, Sharada market recorded the lowest level of contaminants with only three of the samples containing eggs/cysts. However, among all the (5) samples collected, onions recorded the highest contamination, followed by cabbage and lettuce having the same, then cucumber and lastly carrots. The variation in the level of contamination among these markets may be attributed to the market type and the different water sources and means of display of these vegetables.
\end{abstract}

Keywords: Ascaris lumbricoides; Entamoeba species; Giardia intestinalis; Ganakwari market; Kwa-kwaci market; KofarNaisa market; Sharada market; Kano metropolis; Trichuiris species

\section{Introduction}

Many studies had been conducted to evaluate the role of raw vegetables in the transmission of intestinal parasites in different countries, including Nigeria and have stressed the importance of fruits and vegetables, particularly which are consumed raw and unwashed, in the transmission of medically important parasites. Although fruits and vegetables are source of essential nutrients, vitamins, minerals, proteins, fibers and plays a vital role in protecting the human body from a number of diseases, consuming raw and possibly contaminated vegetables may be responsible for cases of related diseases among the population. Because of poor hygienic practices related to planting, harvesting, packing, transportation, and storage, consumption of fruits and vegetables, could be at risk [1].

Intestinal parasitic infections are widely distributed among population throughout the world, hence endangering public health. Infections with medically important parasites (intestinal helminths and protozoa) are closely linked to conditions including poverty, unsafe water, crowded living conditions, lack of sanitation and hygiene [2]. Nigeria is among the countries with the highest population cases of infections with intestinal parasites in sub-Saharan Africa [3-5]. About one third of the world, population; more than two billion people, are infected with intestinal parasites. Food normally becomes a potential source of human infection via contamination, during production, collection, transport, preparation or processing [6].

Food borne diseases continue to be a common and serious threat to public health all over the world and these diseases are a major cause of morbidity. In addition to causing morbidity and mortality, infection with intestinal parasites are known to cause iron deficiency anaemia, growth retardation in children and other physical and mental health problems [6].

Intestinal parasite infection is linked with the problems of malnutrition and stunted growth [7]. Intestinal parasitic infections 
are transmitted via faecal oral route by eating intrinsically contaminated food or via uptake of free-living parasitic stages from the environment (eggs, cysts and oocysts) $[8,9]$. These parasites are common in fresh vegetables and are reported to harbour intestinal parasite such as Ascaris lumbricoides, Taenia species, Faciola hepatica, Hymenolepis nana, Echinococcus species, Trichuiris species, Enterobius vermicularis, Trichostrongylus species, Toxocara species, Strongyloides stercolaris, Giardia intestinalis, Entamoeba species, Lodamoeba buschlii, Blastocystis hominis and Crypstosporidium parvum [10].

Vegetables comprises of herbaceous plant's roots, stems, leaves or fruits that are fresh and are either eaten fresh or prepared in a number of ways. Vegetables are essential part of a healthy human diet due to their nutritional values [11]. Raw vegetables are main sources of vitamins, dietary fiber and minerals and their regular consumption has been associated with a reduced risk of cardiovascular disease, stroke, certain cancers, lower blood pressure and low density lipoprotein cholesterol. Furthermore, vegetables support and increase retina health and vision, fights harmful free radicals, normalizes and increase digestion time, and boost immune system activity. Vegetables can become contaminated with viral, parasitic, fungal and enteric bacterial pathogens throughout the process of plantation, harvesting, processing, transportation and consumption [5].

Population of urban Kano obtains their vegetables from peri-urban vegetable farms located at different parts of the Kano metropolis. Notable farms include, Kwakwachi, KofarNa'isa, Sharada, GanaKwari, and Janguza market. Most of the water used for irrigating the plants, are from urban waste water channel through major drains or seasonal inner tributaries of Jakara and Kano rivers. It is important to quality assess parasites that interact with the various species of vegetables raised and marketed in urban Kano.

This research work determines the presence of parasites of health importance in selected vegetables (cabbage, lettuce Cucumber, carrot and onions) sold at various markets in Kano metropolis, along with their level of contamination on each of the collected samples.

\section{Methodology}

\section{Ethical approval}

Ethical approval was sought for, from the ethical committee of each of the four different markets namely; 'kwakwaci,' 'KofarNa'isa', 'Sharada', and 'GanaKwari' market, and located in Kano state Nigeria.

\section{Sample collection}

Samples were obtained from different markets located in parts of Kano metropolis at specific times. Notable farms include; 'kwakwaci', 'KofarNa'isa', 'Sharada', and 'GanaKwari', Peri-urban vegetable farms. A total of (25) samples were collected (5) samples each for the kinds of plant species, from each market. The vegetables were obtained randomly, under normal purchase conditions from the selected outlets in the early hours of 8-10 am weekly and placed into clean and sterile polythene bags and labelled accordingly. The samples were transferred to the laboratory for examination within six hours of collection for the presence of parasites, their cysts, oocysts, and helminthes eggs and larvae. The selected vegetable samples included cabbage, (Brassica oleracea), Lettuce (Lactuca sativa), Carrot (Daucus carota), Onions (Alium cepa) and Cucumbers (Cucumis sativus).

Preparation of Sterile Phosphate-Buffered Solution: The method described by Bekeleet al. (2017), was adopted. The procedure was as follows; about $8.5 \mathrm{~g}$ of $\mathrm{NaCl}$ was added to $1,000 \mathrm{ml}$ of distilled water and was gently swirl to ensure an even mixture. This gives a sterile phosphate buffered solution.

Administration of Questionnaire to find out Knowledge and Practice Associated with Vegetable Hygiene: The method described by Adugna E, et al., [7] was adopted. The procedure was as follows; A pre-tested semi-structured questionnaire was used to collect data on factors associated with parasitic contamination of vegetables such as: status of the produce (washed before display or not, freshly collected or stayed more than one day, source of water used for washing the vegetables and educational status of the vendors). Data on means of display, sex of the vendors and the market type were recorded by simple observation. A total of 40 vendors participated in the study.

\section{Sample Preparation and Washing}

The method described by Said DES [12] and Ndamukong-Nyanga JL, et al., [13], were adopted. The procedure was as follows; Two hundred grams of each type of the fresh leafy/fruit vegetables samples were weighed and washed according to the traditional procedure which is generally used for washing vegetables, they were immersed immediately in clean water inside a sink and for left approximately 6-7 min for sedimentation of mud and dust. The samples were gently collected and were put in a plastic basket. Each vegetable sample was eluted by vigorous agitation followed by the sonication of each specimen for $30 \mathrm{~min}$ in the already prepared buffered solution. The eluent was filtered through set of sieve to remove unwanted debris and was allowed to stand on a bench for 10 hours to allow for proper sedimentation. The Supernatant was discarded with a Pasteur pipette leaving about $15 \mathrm{ml}$ at the bottom, and $(10 \mathrm{ml})$ of the deposit mixture was transferred into a centrifuge tube and spun for five minutes at $1,500 \mathrm{rpm}$. The supernatant was decanted by quickly inverting the tube, after which the deposit were mixed and examined as follows:

Simple smear: A drop of the sediment was applied on the centre of a clean grease-free slide. A clean cover slip was placed gently to avoid air bubbles and over flooding. The preparation was examined under a light microscope using $10 \times$ and $40 \times$ objectives.

Iodine smear: A drop of the sediment was mixed with a drop of Lugol's Iodine solution and examined as in simple smear. The simple and iodine smears were used for detection of parasitic eggs, cysts and larva. The process was systematically repeated until the mixture in each test tube was exhausted. Eggs, cysts and oocysts of parasites found under the light microscope were identified as previously described by Cheesbrough M [14].

\section{Microscopic identification of eggs and cysts of parasite species}

The morphological characteristics of parasites were examined, the shapes and sizes of the eggs, the identification guides from the Center for Disease Control (2016), and Cheesbrough M, were employed to obtain appropriate identification of the parasite species [14,15].

However, for an accurate and immediate identification of the observed structure, a calibrated ocular micrometre was used for the accurate measurement of the observed structure as an artifact. An upto-date atlas containing tables of expected sizes and characteristics of various trophozoites, cysts, eggs larvae, and mature forms of human parasites, as well as artifacts that might be encountered in specimens were employed. For accuracy, all observed structures that do not meet the atlas criteria for the identification, were not identified as a parasite $[16,17]$. 
Determination of eggs/parasite density: For the interpretation of the microscopic examination of the level of the parasitic contamination of the vegetables, the method as described by Said DES [12], was adopted.

Each parasite's eggs, cysts or oocysts present in each sample were counted and their densities were categorized as: "many" (' $>3$ ' cysts per high-power field; '>20' eggs per low-power field). "Moderate" ('2' cysts per high power field; 10-19 eggs per-low power field). "Few"' (' 1 ' cyst per high-power field; '3-9' eggs per low power field) and "rare" ('2-5' cysts and ' $<2$ ' eggs per $100 \mu \mathrm{L}$ of sediment). For simplicity, numerical values were assigned to each density: "many: 4", "moderate: 3", "few: 2", "rare: 1 ", and "none: 0 ".

\section{Data analysis}

The results obtained were analysed statistically using descriptive statistics and where necessary relevant. SPSS software for windows version 25.0 was employed.

\section{Results and Discussion}

A total of (25) samples, (5) from each of (cabbage "Brassica oleracea", Lettuce "Lactuca sativa", Carrot "Daucus carota", Onions "Alium cepa" and Cucumbers "Cucumis sativus") were collected from each of the four markets (Kwa-Kwaci Market, KofarNa'isa Market, Sharada Market and GanaKwari market), which are all located in Kano metropolis. Various level of contamination ranging from "Many (100\%), Moderate (75\%), Few (50\%), Rare (25\%), and None (0\%)" were recorded for each of the observed vegetables samples. This contamination was as a results of the presence of eggs and cysts of Ascaris lumbricoides, Trichuiris species, Giardia intestinalis and Entamoeba species. These results were presented in table 1 , table 2 and chart 1 . Among all the four markets, "GanaKawi market recorded the highest number of eggs/cysts, with contaminants in all the samples. These is followed by Kwa-kwaci Market with the presence of eggs/cysts in four samples, Then KofarNa'isa market with all the samples contaminated. Sharada market recorded the least presence of contaminants with only three of the samples containing eggs/cysts. Among all the vegetables samples collected, onions recorded the highest contamination, followed by cabbage and lettuce, followed by cucumber and lastly carrot.

Table 1: The distribution of eggs/cysts of parasite across vegetables samples and markets in Kano state.

\begin{tabular}{|l|c|c|c|c|c|}
\hline Parasite eggs/cysts & Cabbage & Lettuce & Carrot & Onions & Cucumber \\
\hline Ascaris lumbricoides & $\mathrm{B}, \mathrm{C}, \mathrm{D}$ & $\mathrm{A}, \mathrm{B}, \mathrm{C}, \mathrm{D}$ & $\mathrm{A}, \mathrm{C}, \mathrm{D}$ & $\mathrm{A}, \mathrm{B}, \mathrm{C}, \mathrm{D}$ & $\mathrm{A}, \mathrm{B}, \mathrm{C}, \mathrm{D}$ \\
\hline Trichuiris species & $\mathrm{B}, \mathrm{D}$ & $\mathrm{A}, \mathrm{B}, \mathrm{C}, \mathrm{D}$ & $\mathrm{A}, \mathrm{B}, \mathrm{C}, \mathrm{D}$ & $\mathrm{A}, \mathrm{B}, \mathrm{C}, \mathrm{D}$ & $\mathrm{A}, \mathrm{B}, \mathrm{C}, \mathrm{D}$ \\
\hline Giardia intestinalis & $\mathrm{A}, \mathrm{B}, \mathrm{D}$ & $\mathrm{A}, \mathrm{D}$ & $\mathrm{A}, \mathrm{B}$ & $\mathrm{A}, \mathrm{C}, \mathrm{D}$ & $\mathrm{A}, \mathrm{B}, \mathrm{D}$ \\
\hline Entamoeba species & $\mathrm{A}, \mathrm{D}$ & $\mathrm{A}, \mathrm{B}, \mathrm{C}, \mathrm{D}$ & $\mathrm{A}, \mathrm{B}$ & $\mathrm{A}, \mathrm{B}, \mathrm{C}, \mathrm{D}$ & $\mathrm{A}, \mathrm{C}, \mathrm{D}$ \\
\hline
\end{tabular}

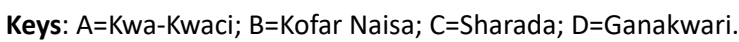

Table 2: The various level of egg/parasite density in each of the four markets.

\begin{tabular}{|l|c|c|c|c|c|}
\hline \multicolumn{1}{|c|}{ Market } & Cabbage & Lettuce & Carrot & Onions & Cucumber \\
\hline Kwa-Kwaci & 0 & 3 & 1 & 2 & 1 \\
\hline KofarNaisa & 1 & 1 & 1 & 1 & 2 \\
\hline Sharada & 0 & 2 & 1 & 1 & 0 \\
\hline Ganakwari & 3 & 2 & 1 & 4 & 1 \\
\hline
\end{tabular}

Keys: $0=$ None; $1=$ Rare eggs/cyst; $2=$ =Few eggs/cyst; $3=$ Moderate eggs/ cyst; 4=Many eggs/cyst.
The presence of these eggs/cyst in the various samples and the variation may be attributed to the source of water used in washing the vegetables (Tap, river or well water), the method of display (opened, partially covered or placed on ground), the type of the market (local or peri-urban), and the level of education (educated or non-educated), of the various vendors [6]. The variation in the level of contamination of these vegetables among these different markets may also be attributed to these factors, as different market utilizes different means of display of these vegetables, different water sources and varies in the type of each market as others may be local or peri urban [3]. The use of waste water and insufficiently treated waste water for irrigation in many developing countries, to irrigate vegetables, the failure to control vectors due to ineffective interventions, insecticide resistance, lack of resources, and suspension of surveillance and control measures, climatic factors which favours the growth of many parasites, e.g. stagnant water following rainfall $[7,18]$ are is directly responsible for the high rates of contamination with pathogenic parasites, the contamination of soil with animal wastes and increased application of improperly composted manures to soil in which vegetables are grown also play a significant role in parasite contamination of green vegetables; bad hygienic practices during production, transport, selling, processing and preparation by handlers including consumers, contribute seriously in vegetable contaminations $[6,12,19]$.

Questionnaires were used to obtain various data on the status of the vegetables such as; (washed before display, freshly collected, source of water used for washing, sex of the vendor, age of the vendor, residence of the vendor, educational status of the vendor, means of the vegetables display and the type of the market (local market or peri-urban market). The data obtained were presented in table 3 , table 4 and table 5 as well as in chart 2 , chart 3 , chart 4 , chart 5 , chart 6 , chart 7 , chart 8 , chart 9 and chart 10 .

The findings of the present study, reveals a high number of vegetables that are neither washed nor cleaned before display. The result of these findings is presented in (Chart 2). The high level of un-freshly collected samples recorded in Kwa-kwaci and KofarNa'isa market (Chart 3) create room for many parasitic cysts, oocysts and eggs or trophozoites to sets in, thereby posing a more health risk to the end consumers. Chart 4 shows the Percentage of "Source of Water for Washing the Vegetables". The use of river water, well and or any form of water (Chart 3) from an untreated source can possibly contributes to the contamination of the vegetables with eggs and or cysts of various parasites. Ahmad Eraky MA, et al., [20] reported that the use of any form of untreated water in the washing and or processing of vegetables stand a higher risk of supplying the vegetables with many forms of intestinal parasites and or their products. Chart 5 shows the Percentage of "Sex of the vendor" Collected from each of the Four Markets, where Kwa-kwaci market and Ganakwari market have the highest number (90\%) of male vendors while KofarNa'isa market have the highest number (30\%), of female vendors.

The age range " $21-25,31-35,36-40$ " and " $45-50$ "as presented in (Chart 6) recorded the highest observation, while the age 15-25 and 26-30 recorded the lowest observations. The age of the various vendors might play a role in the spread of the vegetables contamination as young and elderly might possibly boycott the normal washing protocols of the vegetables [8]. However, the place of residence of the vendors (Chart 7) might also play a role in increasing or reducing the level of contaminations of these vegetables. On the educational status of the vendors, chart 8 and chart 9 present these categories, where each of the four markets recorded a varying age of different vendors. However, $45 \%$ of the vendors are within the secondary stage, and this might 


\section{Chart showing the level of egg/parasite density in each of the four Markets}

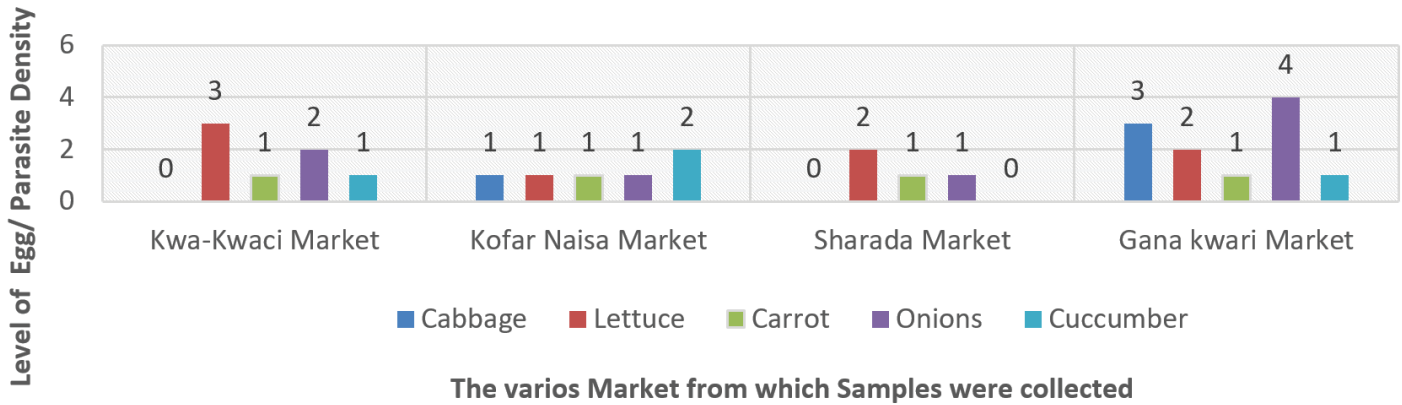

Chart 1: The level of egg/parasite density in each of the four markets.

Chart Keys: 4=Many eggs/cyst (100\%); 3=Moderate eggs/cyst (75\%); 2=Few eggs/cyst (50\%); 1=Rare eggs/cyst (25\%); 0=None (0\%).

Table 3: The various data obtained from the questionnaire "washed before display, freshly collected, source of water for washing, sex of the vendor and type of the market.'

\begin{tabular}{|c|c|c|c|c|c|c|c|c|c|c|c|}
\hline \multirow[t]{2}{*}{ Market } & \multicolumn{2}{|c|}{ Washed Before Display } & \multicolumn{3}{|c|}{ Freshly Collected } & \multicolumn{3}{|c|}{$\begin{array}{l}\text { Source of Water } \\
\text { for Washing }\end{array}$} & \multicolumn{2}{|c|}{ Sex of the Vendor } & \multirow[t]{2}{*}{ Type of Market } \\
\hline & Yes & No & Yes & Stayed One day & More than & Tap & River & well & Male & Female & \\
\hline Kwa-kwaci & 4 & 6 & 2 & 5 & 3 & 4 & 1 & 5 & 9 & 1 & Local \\
\hline kofarNaisa & 3 & 7 & 1 & 5 & 4 & 3 & 1 & 6 & 7 & 3 & Peri-urban \\
\hline Sharada & 6 & 4 & 6 & 1 & 3 & 6 & 0 & 4 & 8 & 2 & Peri-urban \\
\hline Ganakwari & 2 & 8 & 4 & 4 & 2 & 3 & 2 & 5 & 9 & 1 & Local \\
\hline
\end{tabular}

Table 4: The various data obtained from the questionnaire "age of the vendor, and the residence of the vendor" from each of the four markets.

\begin{tabular}{|c|c|c|c|c|c|c|c|c|c|}
\hline \multirow[t]{2}{*}{ Market } & \multicolumn{7}{|c|}{ Age of the Vendor } & \multicolumn{2}{|c|}{ Residence } \\
\hline & $15-20$ & $21-25$ & $26-30$ & $31-35$ & $36-40$ & $41-45$ & $45-50$ & Village & Town \\
\hline Kwa-kwaci & 2 & 1 & 0 & 5 & 0 & 0 & 2 & 1 & 9 \\
\hline kofarNaisa & 1 & 3 & 1 & 1 & 2 & 0 & 2 & 2 & 8 \\
\hline Sharada & 0 & 3 & 2 & 0 & 3 & 1 & 1 & 1 & 9 \\
\hline Ganakwari & 0 & 0 & 0 & 4 & 3 & 3 & 0 & 3 & 7 \\
\hline
\end{tabular}

Table 5: The various data obtained from the questionnaire "educational status of the vendors, and the means of display" from each of the four markets.

\begin{tabular}{|c|c|c|c|c|c|c|c|c|c|}
\hline Market & \multicolumn{5}{|c|}{ Educational Status } & \multicolumn{5}{c|}{ Means of display } \\
\hline & Primary & Secondary & Tertiary & Not Educated & Opened & Covered & Partially Covered & Place on Ground & Place on a Surface \\
\hline A & 4 & 3 & 0 & 3 & 4 & 2 & 1 & 1 & 2 \\
\hline B & 4 & 5 & 1 & 0 & 8 & 0 & 0 & 2 & 0 \\
\hline C & 4 & 5 & 1 & 0 & 2 & 1 & 4 & 0 & 3 \\
\hline D & 1 & 5 & 0 & 4 & 6 & 0 & 0 & 2 & 2 \\
\hline
\end{tabular}

Keys: $A=K w a-k w a c i$ market; $B=$ kofarNaisa market; $C=$ Sharada market; $D=$ Ganakwari market.

contribute to the unhygienic conditions of the vegetables indicating a possible means for contamination. On the means of display, all the markets reveal an alarming levels of the unhygienic means of display employed (samples placed on ground and uncovered) while selling these products. These, indicates a possible means for the contamination of these vegetables. Majority of the factors that contribute in the transmission of the medically important parasites are directly related to poor health, environmental, food and water contamination along with other poor personal hygiene practices [3]. These factors are indeed a serious challenge faced by many underdeveloped along with other developing countries, especially in Africa where the prevalence of parasitic contamination of food and water is always in the increase [8]. However, following a parasitic infection, a number of factors plays a role for their disease manifestation. Conversely, not all parasitic 


\section{Washed befoe display}

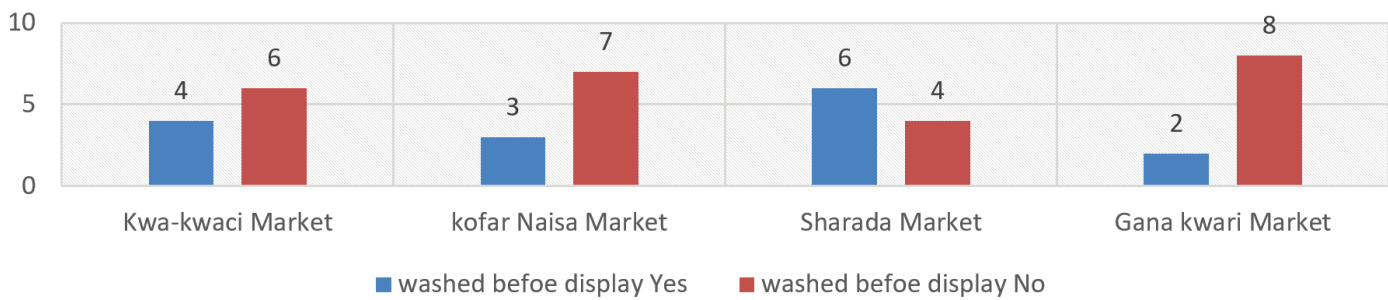

Chart 2: The percentage of "washed before display" of the samples collected from each of the four markets.

Chart Keys: 1=10\%; 2=20\%; 3=30\%; 4=40\%; 5=50\%; 6=60\%; 7=70\%; 8=80\%; 9=90\%; 10=100\%.
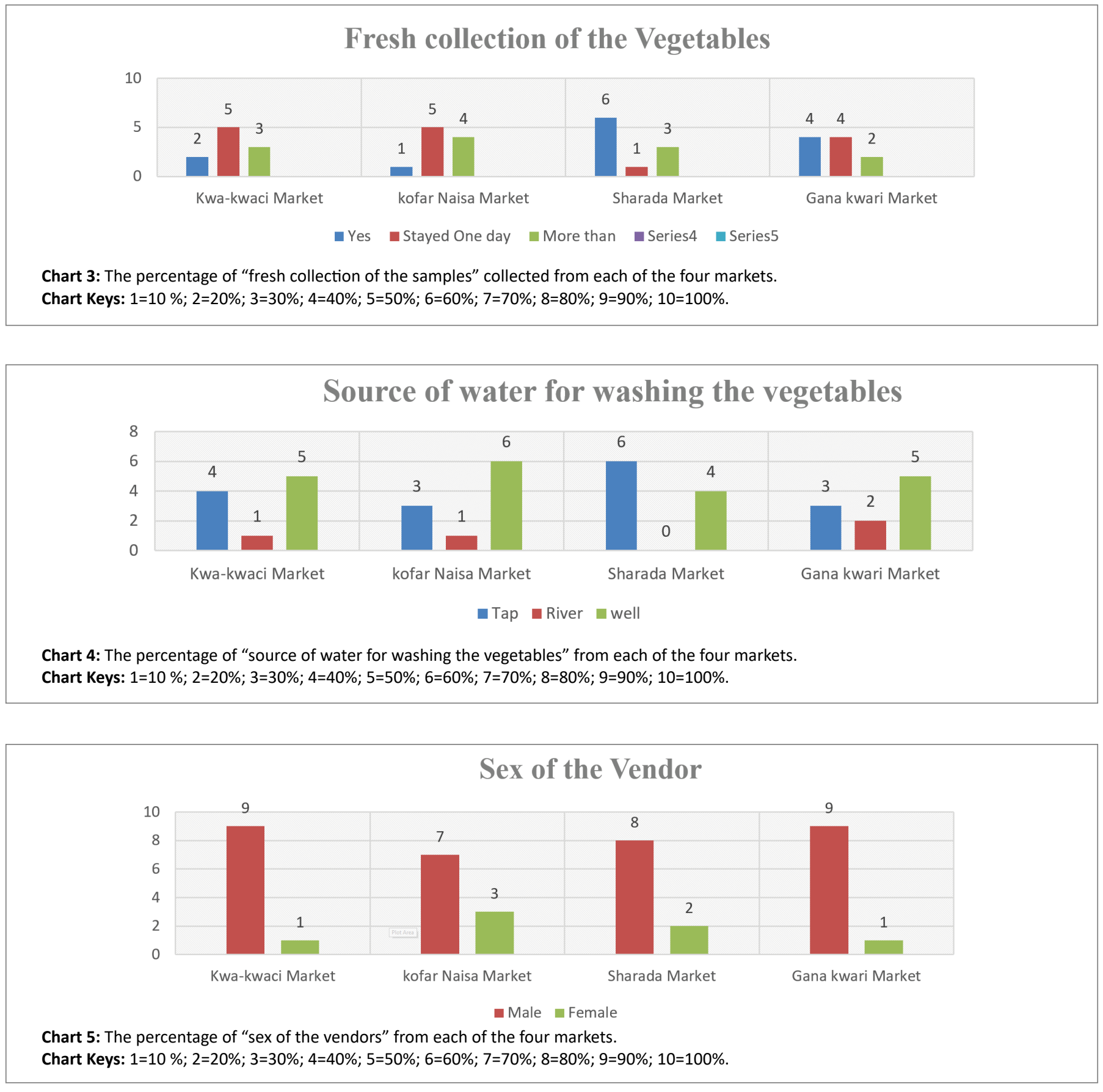


\section{Age of the Vendor}

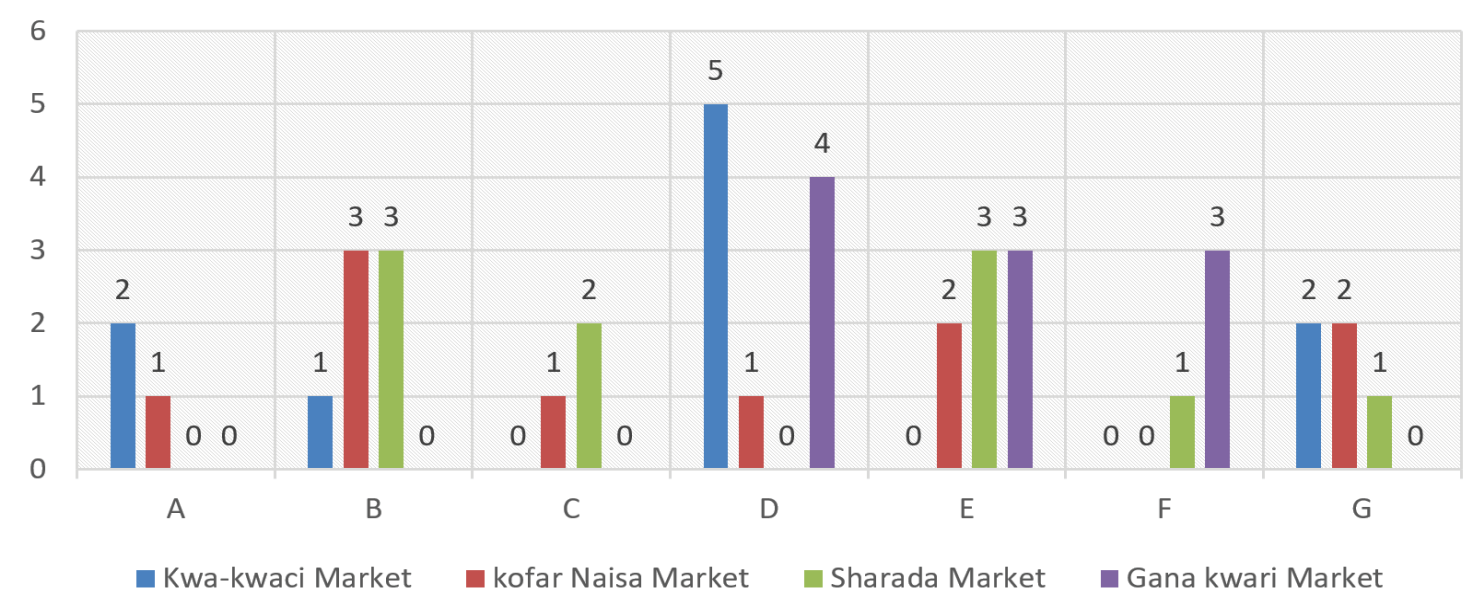

Chart 6: The percentage of "age of the various vendors" from each of the four markets.

Chart Keys: $1=10 \% ; 2=20 \% ; 3=30 \% ; 4=40 \% ; 5=50 \% ; 6=60 \% ; 7=70 \% ; 8=80 \% ; 9=90 \% ; 10=100 \% ; A=15-20 ; B=21-25 ; C=26-30 ; D=31-35 ; E=36-40$; $\mathrm{F}=41-45 ; \mathrm{G}=45-50$.
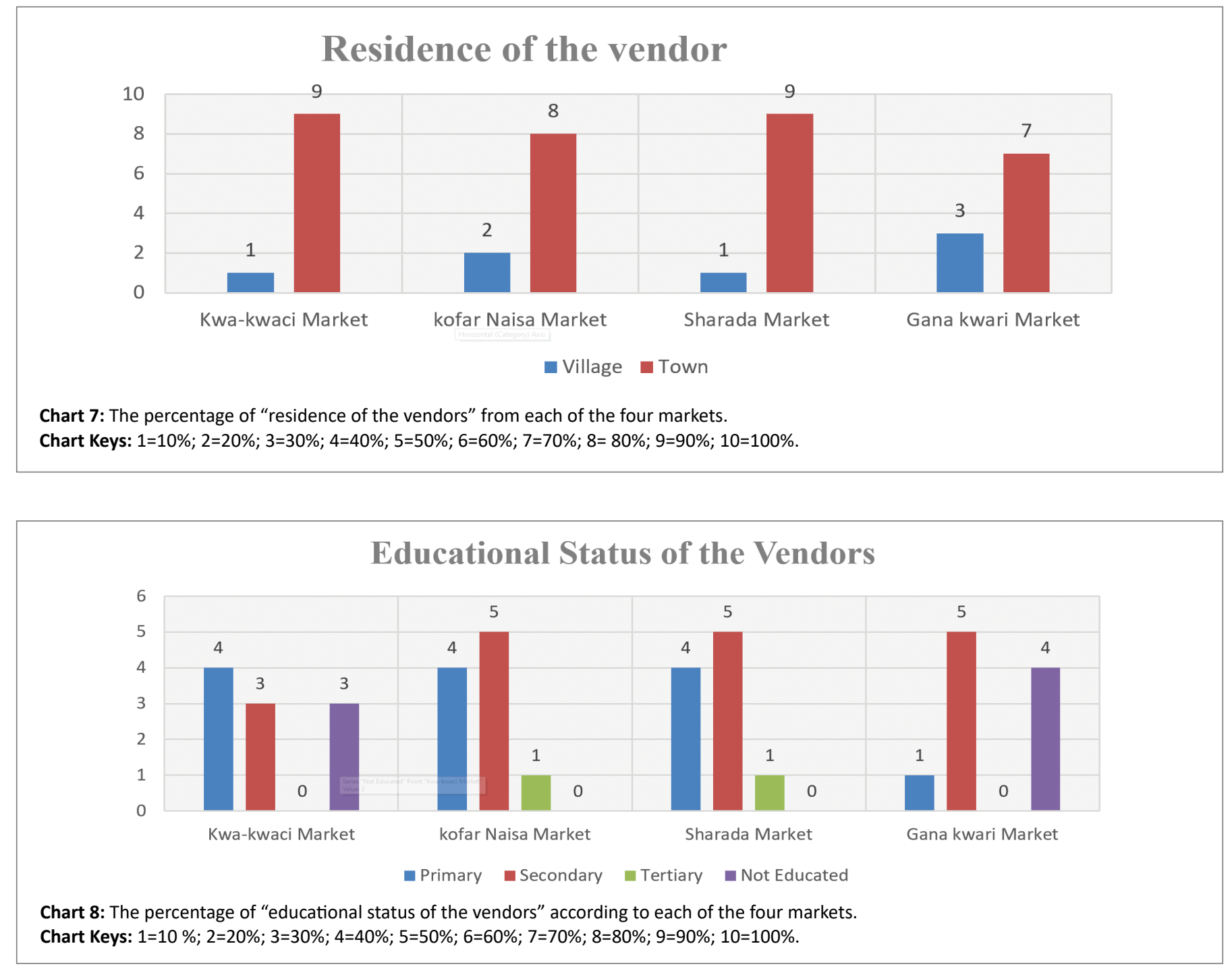


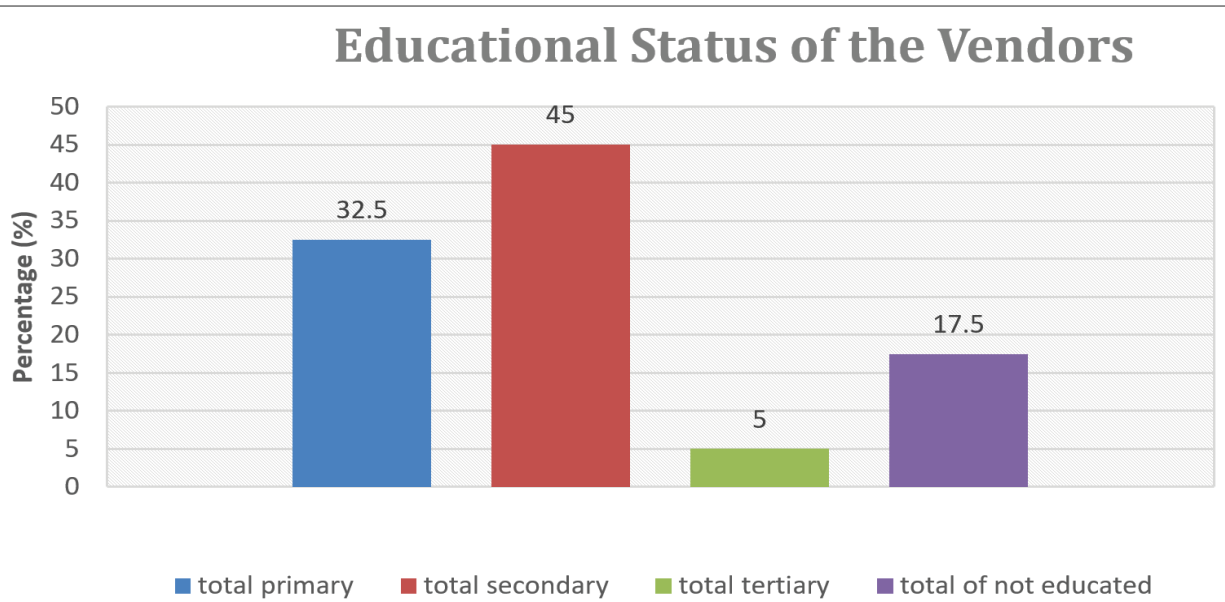

Chart 9: The percentage of "educational status of the vendors" according to each educational category.

\section{Means of Display of Vegetables}

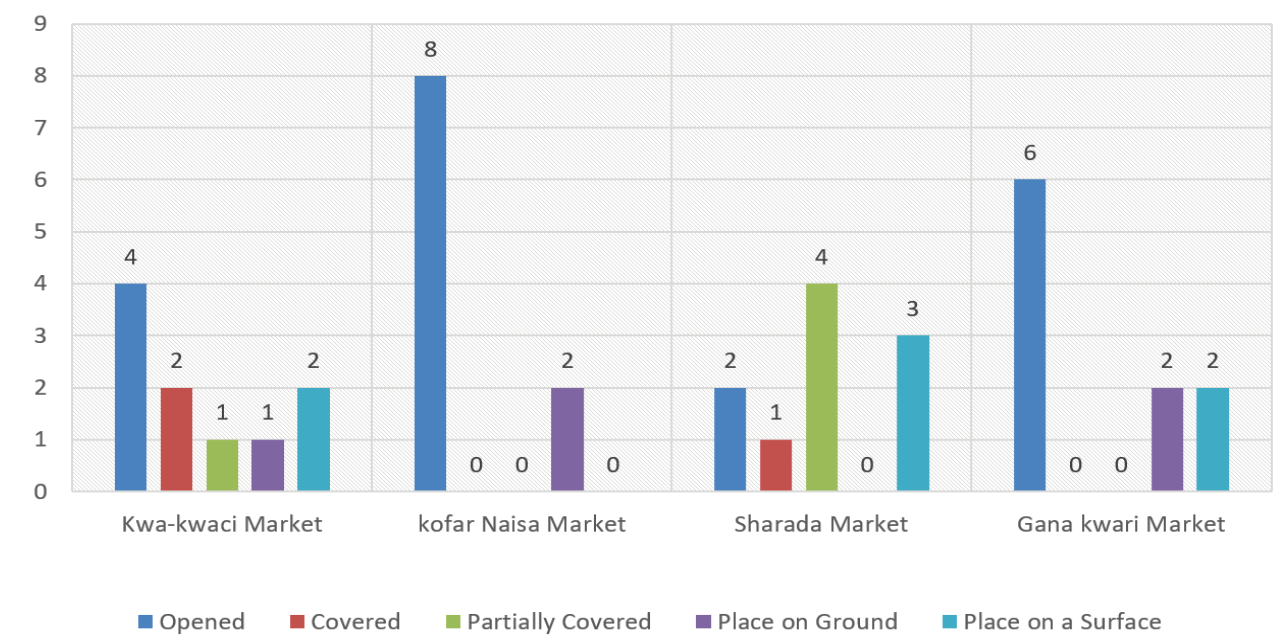

Chart 10: The percentage of "the means of display of vegetables" from each of the four markets.

Chart Keys: $1=10 \%$; $2=20 \%$; 3=30\%; 4=40\%; 5=50\%; 6=60\%; 7=70\%; 8=80\%; 9=90\%; $10=100 \%$.

infections cause disease of clinical significance. Both parasitic factors (Strain of parasite and adaptation to a human host, parasite load, Site(s) occupied in the body and metabolic processes of the parasite particularly the nature of any waste products or toxins produced by the parasite) along with the host factors (Genetic factors, Age and level of natural immunity, Intensity and frequency of infection, Presence of co-existing disease or condition which reduces natural immune responses, e.g. pregnancy, or infection with HIV, whether there is under nutrition or malnutrition, Life style and occupation) plays an important role for the onset of the disease [21].

\section{Recommendation}

i. The high use of river and other untreated water for washing and or processing of vegetables should strictly be avoided as it brings about the contamination of these vegetables with medically important parasites, their cysts, eggs, trophozoites and or larvae. ii. There should be strict regulation to ensure the overall hygienic handling of all vegetables and other food items in these four markets namely, Kwa-kwaci market, KofarNa’isa market, Sharada Market, and Ganakwari market.

iii. There should be an assessment on the level of contaminations of each vegetable by relevant authorities before their sales and subsequent consumption.

iv. There should be regular enlightenment and awareness program to the farmers on medically important parasites along with their public health burden.

\section{Conclusion}

The analysis of the various vegetables samples (cabbage, lettuce Cucumber, carrot and onions) collected, from different markets (Kwakwaci market, KofarNa'isa market, Sharada market and Ganakwari 
market, all located within Kano metropolis reveals the presence of various parasite/cysts which are of public health importance. The level of parasitic/cysts contamination of these vegetables varies among these markets. Different samples recorded different level of contaminations. Among all the four markets, "GanaKawi market recorded the highest level contaminants (eggs/cysts) in all the samples. These are followed by Kwa-kwaci Market with four contaminated samples. These are followed by KofarNa'isa market with all the samples contaminated but with some fewer number contaminants. However, Sharada market recorded the least presence of contaminants. However, among all the vegetables samples collected, onions recorded the highest contaminants, followed by cabbage and lettuce, followed by cucumber and lastly carrot. However, this contamination is attributed to the contaminated water used in washing these vegetables, the storage conditions along with the nature of the vegetables display in markets and the unhygienic practices in the handling of these vegetables.

\section{Declarations of Interest}

Each author declares that he or she has no any conflict of interest in connection with this article, and take responsibility of the data and the accuracy of the data analysis.

\section{References}

1. Bekele F, Tefera T, Biresaw G, Yohannes T (2017) Parasitic contamination of raw vegetables and fruits collected from selected local markets in Arba Minch town, Southern Ethiopia. Infect Dis Poverty 6: 19.

2. Mercanoglu Taban B, Halkman AK (2015) Do leafy green vegetables and their ready-to-eat RTE salads carry a risk of foodborne pathogens? Anaerobe 17: 286-287.

3. Oke-Simon, IA, Afolabi OJ, Obasola OP (2014) Parasitic Contamination of Fruits and Vegetables Sold at Akure Metropolis, Ondo State, Nigeria. Researcher 6: 30-35.

4. Al-Megrin WAI (2010) Prevalence of intestinal parasites in leafy vegetables in Riyadh, Saudi Arabia. Int J Zool Res 6: 190-195.

5. Ishaku AA, Ishakeku D, Agwale S (2013) Prevalence of parasitic contamination of some edible vegetables sold at Alhamis market in lafiametropolist. Scholarly Journal of Biotechnology 2: 26-29.

6. Bekele F, Shumbej T (2019) Fruit and vegetable contamination with medically important helminths and protozoans in Tarcha town, Dawuro zone, South West Ethiopia. Res Rep Trop Med 10: 19-23.

7. Adugna E, Belay T, Desalegn B, Firehiwot T (2018) Detection of Medically Important Parasites in Fruits and Vegetables Collected from Local Markets in Dire Dawa, Eastern Ethiopia. Global Journal of Medical Research.
8. Mohamed MA, Siddig EE, Elaagip AH, Edris AM, Nasr AA (2016) Parasitic contamination of fresh vegetables sold at central markets in Khartoum state, Sudan. Ann Clin Microbiol Antimicrob 15: 17.

9. Ndamukong-Nyanga JL, Kimbi HK, Sumbele IUN, Nana Y, Bertek SC, et al. (2017) A Cross Sectional study on the influence of Altiitude and urbanization on the coinfection of malaria and Soil-transmitted helminthes in FakoDivisionm, south West Cameroon. International Journal of Tropical Diseases and Health 8: 150-164.

10. World Health Organisation (WHO) and Food and Agriculture Organization of the United Nations (FAO) Rome (2018).

11. Cheesbrough M (2009) District Laboratory Practice in Tropical Countries, $2^{\text {nd }}$ edition part II. Cambridge University Press, New York.

12. Said DES (2012) Detection of parasites in commonly consumed raw vegetables, Alexandria Journal of Medicine 48: 345-352.

13. Ndamukong-Nyanga JL, Akuma CA, Ndamukong NC, Nji DN (2018) Parasitic helminths of medical importance and yeast infection on fruits sold in the markets and streets of buea, fako division, south west region, Cameroon. wjpmr 4: 257-263.

14. Cheesbrough M (2006) District Laboratory Practice in Tropical Countries, $2^{\text {nd }}$ edition part II. Cambridge University Press, New York.

15. World Health Organization (WHO) (2016) De-worming for health and development. Report of the third global meeting of the partners for parasite control. World Health Organization, Geneva.

16. Elahi R, Kheirabadi YP, Nader A, Gholamalizade M, Dehkodi HA (2018) The Effect of Washing Procedures on Contamination of Raw Vegetables with Nematodes Larvae. Asian J Pharm 12: S498.

17. Delesa DA (2017) Intestinal Parasitic and Bacteriological Contamination of Raw Vegetables from Selected Farms and Markets in Nekemte, Ethiopia. Int J Adv Res Biol Sci 4: 191-200.

18. Centre for Disease Control (CDC) (2018) Division of Nutrition, Physical Activity, and Obesity, National Centre for Chronic Disease Prevention and Health Promotion.

19. Centre for Disease Control and Prevention (CDC) (2016) DPDX Global Health-Division of Parasitic Diseases and Malaria.

20. Ahmad Eraky MA, Rashed S, Nasr ME, El-Hamshary M, El- Ghannam AS (2014) Parasitic contamination of commonly consumed fresh leafy vegetables in Benha, Egypt. J Parasitol Res 24: 610-619.

21. World Health Organization (WHO) (2002) Food borne Diseases, Emerging. 